\title{
UNA TEORÍA REALISTA DE LA INTERPRETACIÓN ${ }^{\mathrm{I}}$ \\ A Realistic Theory of Interpretation
}

Michel Troper

Universidad Paris-Nanterre, Francia ${ }^{2}$

\begin{abstract}
Resumen
Este artículo propone una teoría realista de la interpretación cuyo rasgo distintivo es la idea de que la interpretación es, en realidad, una actividad relacionada con la voluntad y no con el conocimiento. Su objeto son enunciados o hechos, no normas en sentido estricto. La interpretación jurídica, en cuanto "interpretación auténtica", es tendencialmente libre y constitutiva de su validez, aunque ella está sujeta, también, a diversas "restricciones jurídicas" que limitan la actividad del intérprete.
\end{abstract}

\section{Palabras clave}

Interpretación jurídica, Realismo jurídico, Restricciones jurídicas.

\begin{abstract}
This article proposes a realistic theory of interpretation whose distinctive feature is the idea that interpretation is an activity related to will and not to knowledge. Its object is statements or facts, not norms in the strict sense. Legal interpretation, as an "authentic interpretation", is tendentially free and constitutive of its validity, although it is also subject to various "legal constraints" that limit the activity of the interpreter.
\end{abstract}

\section{Keywords}

Legal Interpretation, Legal Realism, Legal Constraints.

Si aplicásemos el método recomendado por nuestros maestros, tendríamos que comenzar por explicitar el título y dar algunas definiciones, comenzando por la interpretación, que es objeto de teorías rivales: de una teoría realista y de otras teorías (que es muy temprano para osar llamarlas "irrealistas"). Después de haber definido a la "interpretación" como una actividad, podremos pasar a la definición de la "teoría realista” y finalmente examinar de qué manera esta teoría se aplica a la interpretación.

Sin embargo, este método no puede ser usado aquí sin tomar precauciones. Para definir a la interpretación se debería, en efecto, escoger entre dos posibilidades: interpretar es describir el significado de algo o es decidir tal significado. La primera definición reposa sobre el presupuesto de que es posible conocer el significado, que la interpretación es una función del conocimiento; la segunda, en cambio, que es una función de la voluntad. Cada una de estas definiciones corresponde a una teoría diferente. La definición no conlleva entonces una actividad que puede ser objeto de una teoría, ella misma es la expresión de esa teoría.

\footnotetext{
${ }^{1}$ Traducción de Irina Burgaentzle del artículo: "Une théorie réaliste de l'interpretation”, de Michel Troper (2006). En algunos casos se ha consultado la traducción de Riccardo Guastini del texto original "Una teoria realista dell'interpretazione" (Troper, 1999). Revisado por Mauricio Maldonado Muñoz.

${ }^{2}$ Profesor emérito de la Universidad Paris-Nanterre (Francia).
} 
Por otro lado, las dos teorías referidas reposan sobre presupuestos ontológicos y epistemológicos.

Ontológicos: si pretendo que interpretar es indicar un significado, presupongo la existencia de un sentido objetivo susceptible de ser descrito. Pero puedo también suponer, justo a la inversa, que el significado no existe, y que, entonces, no es posible describirlo, sino solamente decidirlo.

Además, presupuestos epistemológicos: toda teoría tiene lugar dentro de un sistema intelectual al cual podemos asignar una cierta función. Así, puede considerarse a un discurso práctico — el de los jueces, por ejemplo— como el sistema de referencia, y adoptar la definición de la interpretación que brindará los mejores servicios a efectos del ejercicio de la actividad judicial. Por ejemplo, según Georges Vedel, el juez no podrá ejercer su actividad, ganar legitimidad y argumentar, si no presupone que esta consiste en el descubrimiento de un significado ${ }^{3}$. Como alternativa, se puede tomar a un sistema científico como el sistema intelectual de referencia. En ese caso, habrá que buscar, no la teoría que brindará los mejores servicios, sino aquella que satisfaga las condiciones de veracidad de esta ciencia.

Hay que notar que los dos presupuestos, ontológico y epistemológico, están unidos: escogemos una ontología en función de la tarea que nos hemos asignado. Si nuestra ambición es aquella de contribuir, con la teoría de la interpretación, a un sistema científico, entonces tenemos que escoger una ontología que permita una verificación de tipo científico.

Además, si se quiere evitar todo compromiso precipitado, se debe definir a la interpretación como una "actividad que consiste en describir o decidir el significado" de una cosa. Es necesario, además, introducir una precisión importante, que servirá de argumento en favor de la teoría realista: la interpretación que se tratará es exclusivamente la interpretación jurídica, es decir, aquella que produce efectos en el sistema jurídico, excluyendo en consecuencia la interpretación musical o literaria, que deben ser tratadas de manera diferente.

Ahora se puede definir la teoría realista. Se trata de una variante del positivismo jurídico, por lo tanto, de una doctrina que quiere esforzarse en construir una ciencia del derecho sobre un modelo derivado de las ciencias empíricas. El positivismo jurídico puede presentarse bajo dos formas: ciertas teorías, pertenecientes a la corriente normativista, toman por objeto a las normas en tanto que "deber-ser", y se dan como tarea describir este deber-ser según métodos específicos diferentes de las ciencias naturales; otras tienen una verdadera orientación empírica, y conciben a las normas como comportamientos humanos o expresiones lingüísticas.

También la teoría realista comprende en sí misma diversas variantes. La una tiene como objeto el comportamiento de los jueces, por tanto, un fenómeno psicosocial. El derecho es entonces concebido como una conducta real, como un comportamiento efectivo. Otra variante toma como objeto no las conductas, sino el modo efectivo de razonar real de los juristas. Esta busca entender las "restricciones" que pesan sobre estos actores sociales - $\mathrm{y}$, contemporáneamente, el margen de discrecionalidad del cual disponen-y qué vínculos producen.

Parece ser que Kelsen se adhirió a una teoría realista de la interpretación a partir de la segunda edición de la Teoría pura, a pesar de haberla criticado con términos muy duros. No obstante, no desarrolló completamente tal teoría y no aceptó todas las consecuencias lógicas de esta, poco compatibles con ciertas ideas suyas relativas a la estructura del orden jurídico.

La que expondré aquí, si bien se basa en la concepción kelseniana de la interpretación, se alejará en varios puntos.

\footnotetext{
${ }^{3}$ G. Vedel ha sostenido esta opinión en una intervención inédita presentada en un seminario celebrado en el Centre de Philosophie du droit de la Universidad París II. Un resumen puede encontrarse en M. Troper (1995) "La liberté d'interprétation du juge constitutionnel".
} 
Esta teoría realista puede ser resumida en tres proposiciones principales:

(1) la interpretación es una función de la voluntad y no del conocimiento;

(2) no tiene como objeto normas, sino enunciados o hechos;

(3) confiere a quien la ejerce un poder específico.

\section{Una función de la voluntad}

Tres series de argumentos militan en favor de la tesis de que la interpretación es una función de la voluntad: la interpretación contra legem no existe; no hay un significado a descubrir; no hay una intención del autor; no hay un significado objetivo independiente de las intenciones.

\subsection{La interpretación "contra legem" no existe}

Se puede retomar aquí la distinción establecida por Kelsen entre la interpretación científica y la interpretación auténtica. La interpretación "científica" o "doctrinal" es aquella que es producida no solamente por la ciencia del derecho o la doctrina jurídica, sino por quienquiera que no esté habilitado por el orden jurídico a dar una interpretación dotada del monopolio de la validez.

Kelsen emplea la expresión "interpretación auténtica” en un sentido ligeramente diferente del sentido habitual. En la lengua jurídica clásica, la interpretación auténtica es aquella que emana del autor mismo del texto a interpretar: por ejemplo, el poder legislativo para las leyes, conforme al adagio ejus est interpretari legem cujus est condere. Para Kelsen, la interpretación auténtica es aquella a la que el ordenamiento hace producir efectos jurídicos. Esta puede emanar de cualquier autoridad habilitada para interpretar, por ejemplo, aunque no exclusivamente, de los tribunales superiores. El efecto de la interpretación auténtica es que esta se impone, cualquiera sea su contenido. El texto interpretado no tiene y no puede tener otro significado que aquel dado por la autoridad habilitada, incluso si este significado parece contrario a todas las interpretaciones dadas por otras personas, incluso si parece irrazonable, e incluso si va en contra de lo que se puede saber de la intención del autor del texto.

En cualquier historia de la jurisprudencia se encuentran numerosos ejemplos de tales interpretaciones que se imponen en contra de toda comprensión intuitiva. Un ejemplo es aquel del Conseil d'État interpretando la formula "no susceptible de recurso alguno" en el sentido de que no excluye el recurso "por exceso de poder" (dame Lamotte). Así también, en el caso citado por Chaïm Perelman, unos tribunales ingleses que debían condenar a muerte a ladrones de todo objeto de un valor superior a 2 esterlinas y que, para evitar pronunciar condenas tan duras, valoraban cualquier objeto en 39 chelines, inclusive un maletín que contenía 10 libras esterlinas en billetes (también avaluado en 39 chelines).

Tales interpretaciones no pueden ser dichas contra legem. La única interpretación contra legem, en efecto, sería aquella que se fuese en contra del verdadero significado de la ley. Sin embargo, no se dispone de ninguna interpretación que permita establecer este verdadero significado al cual se podría comparar el producto de la interpretación auténtica. El único estándar jurídicamente incontestable es aquel que es determinado por la interpretación auténtica.

Sin embargo, sería equivocado creer que el ordenamiento jurídico hace prevalecer arbitrariamente un significado impuesto por una autoridad dotada de un poder de decisión sobre un significado ya existente (pero desplazado por razones de certeza, o sacrificado por una especie de "razón de Estado de derecho"). No hay en realidad, en los textos, ningún significado a descubrir.

\subsection{No hay un significado reducible a la intención del legislador}

Antes que nada, hay que remarcar que, si se asimila el significado a la intención del autor, es decir, a un cierto estado mental, existen numerosos textos para los cuales tal intención no existe. 
El caso más llamativo es aquel de un texto adoptado por un órgano colegiado. Se considera que el autor del texto es la autoridad en su conjunto y no solamente los miembros que votaron por este. Pero una autoridad colegiada no puede tener una intención porque no posee una psiquis. En lo que respecta a la intención de los miembros contemplados individualmente, hay que señalar que es imposible de establecer.

Tomemos el caso de un Parlamento: no todos aquellos que votaron por la adopción del texto se han expresado, y aquellos que lo hicieron pudieron haber mentido sobre sus intenciones. $\mathrm{O}$ incluso, si se han expresado sinceramente, dichas intenciones pueden ser entre ellas muy diversas, incluso contradictorias. Los que votaron por la adopción del texto, sin haberse expresado, pudieron haberlo hecho con las mismas intenciones que aquellas de ciertos oradores, como también con intenciones del todo diferentes. Pudieron haber sido animados por toda suerte de razones: la pereza, la ignorancia, la imitación de sus colegas, el problema de respetar la disciplina del partido. Pero aun suponiendo que todos los miembros del colegiado se hayan podido expresar, que todos hayan sido perfectamente sinceros y que hayan estado todos en el mismo estado psíquico, de cualquier modo no pueden haber tenido una intención concerniente a la situación concreta respecto de la cual el texto ha de interpretarse, porque al momento de su adopción no se podía considerar esta situación concreta, sino solamente una clase de situaciones.

También ocurre a menudo que el autor en el sentido jurídico no es también su autor intelectual. Es lo que sucede cuando un proyecto de ley ha sido preparado por un órgano administrativo y adoptado luego por el Parlamento, o incluso cuando una constitución ha sido adoptada por referéndum. En este último caso, el autor es el "cuerpo electoral", y es evidentemente imposible descubrir una intención común a los millones de electores.

Pero aun si se pudiera realmente determinar el autor y descubrir una intención unívoca, no se podría identificar ese estado mental con un significado del texto; ello, puesto que una identificación tal haría muy difícil la aplicación de las leyes. La aplicación de las leyes sería, en efecto, solo la aplicación de la voluntad del legislador. Es normal, según esta concepción, distinguir la intención del legislador respecto del significado que podría resultar de una interpretación literal o teleológica, porque el legislador pudo no haber querido lo que resulta de esas interpretaciones. Pero si el juez se apega a lo que podría conocer del estado mental del legislador, no podría jamás aplicar la ley a situaciones que este último no consideró, por lo que deberá rehusarse a juzgar. Si el significado del artículo 1384 del Code civil coincide con el estado mental de los redactores del código, este no se podría aplicarse a accidentes causados por máquinas que sus redactores no podrían haber siquiera imaginado.

Por lo demás, si el estado mental del legislador versaba verdaderamente sobre una clase de objetos que conocía, y si el juez debiese determinar si la ley es aplicable a tal objeto (que le parece claramente perteneciente a esta clase), no podrá decir de todos modos que ha aplicado la ley conforme a la intención de su autor. Lo que este último tenía en mente no era el objeto concreto, sino solamente la categoría. En el estado mental real en el cual se encontraba, bien pudo haber descuidado el hecho de que se podría subsumir un día tal o cual objeto en la categoría. Para pretender que se aplica la ley según la intención del legislador, se debe consecuentemente admitir la siguiente construcción: el significado de la ley es el que el legislador tenía en mente en conjunto con todas las consecuencias que debió haber obtenido razonablemente, incluso si no las obtuvo realmente, o que habría obtenido si hubiese podido prestar atención a algún hecho concreto o a otro.

La interpretación conforme a la intención es entonces siempre una construcción de la interpretación. Sin embargo, si el significado no es reducible a la intención, no hay tampoco un sentido objetivo independiente de las intenciones. 


\subsection{No hay un sentido objetivo independiente de las intenciones}

Se puede pensar en descubrir un significado que sea diferente de la intención eventual revelada por los trabajos preparatorios. Sería aquel que se desprende de las palabras del texto o del contexto sistémico en el cual figura, o incluso de la función social o económica que debe realizar la norma. Empero, a estos significados diversos no se puede arribar sino solo a través del empleo de ciertos métodos específicos a cada uno de ellos, el significado literal a través de la interpretación literal, el significado funcional a través de la interpretación funcional, etc. Ahora bien, estos diversos métodos conducen a resultados diferentes entre los cuales no se puede decidir sino mediante una decisión. Por ende, es la decisión del intérprete, consistente en hacer prevalecer un método sobre otro, lo que produce el significado.

No hay entonces un significado objetivo, ni en la intención del legislador ni independientemente de esta intención. El único significado es aquel que se desprende de la interpretación, y se puede decir que, previamente a la interpretación, los textos no tienen todavía ningún significado, sino que están solamente a la espera de ser interpretados. De esto se derivan ciertas consecuencias teóricas importantes para la determinación del objeto de la interpretación.

\section{El objeto de la interpretación}

Si el significado no preexiste a la interpretación, y si es solamente su producto, entonces, contrariamente a lo que piensan ciertos autores —incluso el mismo Kelsen_-, el objeto de la interpretación no puede ser una norma jurídica. Si una ley contiene la formula p está prohibido, la expresión $p$ puede designar, según el significado que se le atribuya, múltiples acciones diferentes $p 1, p 2 \ldots p n$, de manera que la ley no contiene una norma, sino, según la interpretación dada, múltiples normas potencialmente diferentes: está prohibido p1, está prohibido p2... está prohibido $p n$. Es el intérprete el que decide entre estas normas diferentes. La norma no está entonces dotada de un significado. Es ella misma un significado, y no puede ser a la vez interpretada, porque es evidentemente absurdo buscar determinar el significado de un significado.

Lo que puede ser objeto de una interpretación es, entonces, solamente lo que puede ser portador de un significado, el texto o el hecho.

\subsection{El texto}

El texto debe ser siempre objeto de una interpretación, y no solamente si es oscuro. Según un conocido adagio, in claris cessat interpretatio o in claris non est interpretandum: lo que es claro no es necesario que sea interpretado. Pero esta idea se enfrenta a varias objeciones. En primer lugar, si la interpretación es una decisión, entonces también puede ser sobre el carácter claro u oscuro del texto. Una autoridad que goza del poder de atribuir una interpretación auténtica puede perfectamente declarar que un texto es oscuro para justificar interpretarlo, o, al contrario, que es claro, de modo de poder afirmar que tiene un significado cierto, sin reconocer que lo está interpretando. Así como hace, por ejemplo, el juez administrativo francés con respecto a ciertos actos de manera de evitar remitir la interpretación a alguna otra autoridad. En segundo lugar, el refrán contradice la visión tradicional de la interpretación. Aun si es que se admite que interpretar es conocer un significado preexistente, no se puede afirmar que un texto es claro sin reconocer que se conoce su significado, y entonces que ya se lo ha interpretado. En consecuencia, incluso los textos reputados claros son textos ya interpretados.

Ahora bien, si la interpretación versa sobre un texto, y si todo texto debe ser siempre interpretado, no se debe reducir la interpretación a la sola determinación del contenido del texto, de lo que prescribe. En otros términos, la interpretación no se refiere solo a las disposiciones que componen el texto normativo, sino también a su "régimen jurídico". 
La idea de que se puede interpretar el "régimen jurídico" del texto se deriva de un concepto amplio de interpretación. Si recogemos una piedra podemos preguntarnos si se trata de un objeto natural o de un artefacto (como un objeto prehistórico o un fragmento de construcción). En el derecho, antes de determinar el significado de una disposición, se debe establecer que se trata de una disposición jurídica y que su significado es, justamente, una norma. Si es una disposición jurídica, se debe establecer a qué nivel pertenece. Así, antes de determinar lo que significa la palabra "igualdad" en el texto de la Déclaration des droits de l'homme et du citoyen, o lo que designa en el preámbulo de 1946 la expresión "principios fundamentales reconocidos por las leyes de la República”, el Conseil constitutionnel debe establecer que estos textos son jurídicamente obligatorios y que tienen valor constitucional.

Así, el intérprete puede determinar su propia competencia. El régimen jurídico del texto, en efecto, determina la competencia de la autoridad que la aplica. El poder del juez constitucional, por ejemplo, es generalmente justificado por la idea de que ciertos textos tienen un valor jurídico, que no son simplemente la exposición de una ideología política, que tienen un valor superior al de las leyes y que la función de controlar la conformidad de las leyes a las normas superiores contenidas en estos textos pertenece al juez. Si es el intérprete el que determina el régimen jurídico del texto, determina a la vez los límites de la competencia del legislador y la suya propia.

Esta idea habría sido rechazada por Kelsen. El autor de la teoría pura del derecho, en efecto, distingue cuidadosamente entre el valor jurídico de un enunciado y su contenido. Habría una diferencia importante entre afirmar que un enunciado presenta el carácter de norma (porque, desde un punto de vista dinámico, ha sido formulado por una autoridad competente conforme al procedimiento previsto en una norma superior) y afirmar que tal enunciado posee cierto significado, esto es, que prescribe tal o cual conducta. Por consiguiente, la interpretación no versaría sino solamente sobre el contenido del enunciado (tal conducta y no tal otra está prohibida o permitida), pero no sobre el valor o régimen jurídico (tal enunciado expresa una norma jurídica de rango constitucional). De hecho, es muy comprensible que Kelsen esté atado a esta distinción: esta constituye el único medio para preservar la tesis según la cual un enunciado tiene el significado objetivo de una norma porque así ha sido establecido por el ordenamiento jurídico. Si en efecto un texto presenta el carácter de una ley, porque es conforme a la constitución, poco importa que su contenido de significado sea determinado por un intérprete: la teoría según la cual el significado objetivo de norma conferido por una norma superior es preservado en lo esencial.

No obstante, esta distinción no es aceptable. Se puede sin duda concebir que un intérprete se limite a determinar el contenido de significado y se abstenga de pronunciarse explícitamente sobre su régimen jurídico. Pero se trata de una distinción puramente práctica, y también la actitud inversa es concebible. En la práctica jurídica se encuentran, por otro lado, varios ejemplos de interpretaciones que versaban sobre el régimen jurídico del acto: el Conseil constitutionnel decide que el preámbulo hace parte de la Constitución, el Conseil d'État decide que un boletín es en realidad un acto reglamentario, etc. En realidad, la interpretación del régimen jurídico está siempre implícita en la interpretación del contenido prescriptivo, porque no se puede afirmar que una ley prescribe $p$ sin presuponer que el texto que contiene esta prescripción es una ley y no la declaración de voluntad de un simple particular.

De la idea de que la interpretación versa tanto sobre el régimen jurídico como sobre el contenido del enunciado, se deriva una consecuencia teórica importante relativa al fundamento de la validez. Acerca de la validez se puede dar, para las necesidades de la argumentación, una definición aceptada por varias teorías distintas, aunque, por otro lado, concurrentes: decir que 
una norma es válida significa que pertenece a un orden normativo. Según la teoría kelseniana de la jerarquía de normas, una norma es válida cuando ha sido formulada de conformidad con una norma superior. Pero si se aceptan los elementos de la teoría de la interpretación que se ha expuesto esquemáticamente, un enunciado tiene el significado de una norma, no debido a su conformidad con la norma superior, sino en virtud de que ha sido interpretada por una autoridad habilitada en el sentido de que cierta conducta debe observarse. Es, por ello, el proceso de aplicación y no la conformidad a la norma superior lo que conduce a atribuir a un enunciado el significado objetivo de norma jurídica. Esta idea permite, entonces, evitar dos de las dificultades a las cuales se enfrenta la teoría pura del derecho.

La primera concierne a la norma fundamental. Según Kelsen, visto que cada norma encuentra el fundamento de su validez en una norma superior, la constitución es el fundamento de validez última de todas las normas que pertenecen al ordenamiento jurídico. Pero, como no hay una norma positiva encima de la constitución, esta no puede ser válida, y entonces no puede ser identificada como una norma jurídica de la misma manera que todas las otras normas. No obstante, si no es identificada como norma jurídica, no es apta para fundar la validez de normas inferiores. En consecuencia, se debe necesariamente — si se considera a las normas jurídicas como válidas - presuponer que la constitución es válida. Este presupuesto es la norma fundamental. Kelsen logra refutar la mayoría de las objeciones que le fueron presentadas seńalando que no supone realmente la existencia de una norma fundamental, que esta norma no existe, sino que es solo una hipótesis lógica-trascendental que hacen todos los juristas de manera espontánea y que la teoría pura del derecho revela. El razonamiento de Kelsen es perfectamente admisible, pero no cumple enteramente la función que la teoría pura le asigna: permite comprender por qué los juristas tienen a las normas como válidas, pero no por qué lo son real u objetivamente.

La teoría realista de la interpretación permite evitar esta dificultad. Si es el intérprete el que determina la norma expresada por un enunciado, entonces a la cuestión relativa a por qué la norma es válida, por qué pertenece a un orden jurídico, basta responder lo siguiente: porque ha sido producida en el curso del proceso de interpretación.

La segunda dificultad es epistemológica, y aquí solo se la puede tratar por alusión. Si la validez es percibida como una relación de conformidad entre significados, entonces las proposiciones de derecho - por las cuales la ciencia debe describir normas válidas - no describen hechos empíricos. Los positivistas se encuentran, entonces, confrontados a una tarea enorme: construir una ciencia del derecho sobre el modelo de las ciencias empíricas, aunque ella no tenga por objeto fenómenos empíricos. Al contrario, la teoría realista permite tratar el derecho como un conjunto de hechos empíricos, ya que se trata de actos por los cuales los intérpretes determinan el significado de los enunciados.

Pero la interpretación no versa solamente sobre los enunciados, sino también sobre los hechos.

\subsection{Los hechos}

Si el significado no está presente en el enunciado antes de la interpretación, es porque el enunciado no está "naturalmente" dotado de un significado. Este significado le es solamente atribuido por la interpretación. Pero se puede también atribuir un significado a cualquier hecho (y tampoco los hechos se encuentran dotados de significado in natura). Es lo que se produce en al menos dos casos.

El primero es aquel de la costumbre. Según la definición habitual, la costumbre es una práctica repetida, acompañada del sentimiento del carácter obligatorio de esta práctica. Es entonces un hecho. Pero como un hecho no puede ser productor de derecho, primero 
debe haber una norma que prescriba que habrá que conformar el propio comportamiento a la costumbre, y luego que una autoridad habilitada declare que tal práctica repetida, acompañada de un sentimiento de obligación, constituye una costumbre y que presenta, así, el significado de una norma a la cual hay que adecuar el propio comportamiento.

La interpretación versa aquí sobre la premisa menor de un silogismo (hay que adecuarse a la costumbre; esta es una costumbre; entonces...). La peculiaridad de esta operación consiste en transformar un hecho en una norma.

En realidad, cada vez que la interpretación versa sobre la premisa menor del silogismo, no transforma un hecho en derecho, pero puede sustituirse a la interpretación de un texto. Es lo que se produce con la calificación jurídica de un hecho. Tomemos el caso del famoso fallo Gomel. En términos de la ley, la administración puede negar un permiso de construir si el inmueble proyectado puede afectar a una "perspectiva monumental". Para valorar si un rechazo es legal, el juez puede, o bien decidir el significado de la expresión "perspectiva monumental", o bien decidir si tal lugar posee o no el carácter de una "perspectiva monumental". Si toma el segundo camino, no habría, en apariencia, interpretado el texto, sino solamente calificado el hecho. La operación se presenta como una subsunción: dada una clase, basta con determinar si un objeto presenta los criterios de pertenencia a esta clase para poder incluirlo en ella. Pero, en realidad, no hay una controversia en sí, porque no existe una lista de criterios de pertenencia a la clase: dicho de otra manera, no existe una definición. La afirmación, por parte del juez, de que tal lugar no presenta el carácter de una "perspectiva monumental" no puede, como es evidente, resultar de la sola observación del lugar: esta constituye precisamente una definición de "perspectiva monumental".

En realidad, es como si el juez hubiera interpretado el texto. Por ello, los juristas no se equivocan cuando, para atribuir un significado a una expresión, exponen largas listas de casos en donde el texto que contiene tal expresión ha sido aplicado.

El juez, en efecto, ha determinado la extensión del concepto. Esta definición no puede ser más que un acto de voluntad (un acto voluntario), pero, con relación a la interpretación manifestada del texto, ofrece una doble ventaja. En primer lugar, no se presenta como una interpretación. Admitir que ha interpretado puede ser difícil para el juez cuando, por ejemplo, como en el caso del derecho francés, el derecho positivo no lo habilita expresamente a hacerlo, o incluso más difícil cuando en Francia, bajo la Revolución, el derecho simplemente se lo prohibía. Por otra parte, la calificación del hecho no debe ser justificada mediante la referencia a uno de los métodos de interpretación canónicos, porque esos métodos solo valen para los textos. Finalmente, la calificación del hecho no vale en principio sino solo para el caso en concreto, y entonces el juez, dejando implícita la definición que de cualquier modo ha sido empleada, no se hallará vinculado por sus propias formulaciones.

\section{El poder del intérprete}

Dado que la interpretación es una operación de la voluntad que versa tanto sobre hechos como sobre enunciados, debe ser entendida como el ejercicio de un poder considerable. Analizar este poder es determinar su fundamento, su sede, las normas que permite producir y los límites dentro de los cuales se ejerce.

\subsection{El fundamento de poder}

El fundamento del poder de la interpretación reside en la validez de la interpretación que produce.

En efecto, esta interpretación no es susceptible de ser verdadera o falsa. Esto no depende, como se dice a veces, del hecho de que no exista una interpretación estándar con la cual se podría comparar aquella que emana del intérprete auténtico. La ausencia de una 
interpretación estándar podría solamente servir de argumento a la tesis de que no se puede demostrar la veracidad o falsedad de la interpretación científica, pero no a aquella que concierne al estatuto lógico de la interpretación auténtica. En realidad, no se puede tampoco demostrar la veracidad o falsedad de la interpretación científica. Tampoco esta es lógicamente susceptible de ser verdadera o falsa. Pero, en lo que concierne a la interpretación auténtica, si no puede ser ni verdadera o falsa, es únicamente porque, cualquiera sea su contenido, el orden jurídico le confiere efectos. Esta consiste en la decisión de conferir un significado a un enunciado o a un hecho, y una decisión no puede ser ni verdadera ni falsa, sino solamente válida o inválida en un orden normativo dado.

La validez de la decisión interpretativa es exclusivamente formal, es decir, resulta solo de la competencia jurídica de la autoridad que la adopta y no de su contenido, ni siquiera de los métodos por los cuales es justificada. El hecho de que una autoridad haya recurrido a tal o cual método de interpretación no tiene ninguna incidencia sobre su validez. Esto no se debe a la distinción conocida entre el context of justification y el context of discovery, es decir, al hecho de que la decisión pudo ser tomada por razones del todo diferentes respecto de aquellas que fueron invocadas para justificarla. En efecto, el orden jurídico ata consecuencias no al método (invocado o realmente utilizado), sino solamente al ejercicio, por parte de una autoridad habilitada, de la competencia que le ha sido conferida. ¿Cuál es entonces esta autoridad? ¿Quién debe ser considerado como un intérprete "auténtico"?

\subsection{El autor de la interpretación}

Si la interpretación auténtica es solamente aquella a la que el orden jurídico ata ciertos efectos, la que no puede ser sometida a discusión y que, por consiguiente, en el caso de la interpretación de un texto, se incorpora a ese texto, entonces el intérprete es toda autoridad competente para dar esa interpretación.

Naturalmente, se trata ante todo de las jurisdicciones supremas. Pero existen varias autoridades que poseen competencia para realizar interpretaciones auténticas. Aquellas que, aunque no jurisdiccionales, pueden realizar una interpretación incontestable en el marco de una jurisdicción cualquiera. La constitución francesa de 1958 ofrece algunos ejemplos: solo el presidente de la República es competente para interpretar los términos del artículo 16 y decidir lo que significan las expresiones "amenaza grave e inmediata" o "interrupción en el funcionamiento regular de los poderes públicos”. Por otro lado, se puede notar que la interpretación puede, como en el caso del fallo Gomel, versar, sea sobre el texto, sea sobre las circunstancias. De igual manera, solo el presidente puede decidir que en el artículo 13 la expresión "El Presidente de la República firma las ordenanzas y los decretos deliberados en el Conseil des ministres" significa que tiene el derecho de no firmarlos ${ }^{4}$. Todavía más, es el Parlamento el único que puede decidir lo que es la "alta traición" de la que el presidente de la República puede ser culpable. Y también aquello que había expresado muy bien Gerald Ford, entonces líder republicano del Senado: los "bigh crimes and misdemeanors", que justifican el impeachment del presidente de los Estados Unidos, son lo que decide el Senado.

\footnotetext{
${ }^{4}$ Este poder de interpretación del presidente de la República no ha sido ignorado por los actores políticos como sí por los juristas. Allain Peyreffite, por ejemplo, reporta esta observación del ministro de Broglie en el Consejo de Ministros de 19 de septiembre de 1962, a propósito de la revisión de la constitución mediante el procedimiento del artículo 11: "personne n'a parlé du pouvoir d'interprétation de la constitution par le président de la république. C'est un pouvoir fondamental et, au moins implicitement, inclus dans la constitution. C'est justement dans les cas où les juristes sont divisés entre eux que le Président de la République doit user de ce pouvoir. Il a les moyens de le faire en faisant appel au peuple souverain, suivant le droit qui lui en est expressément reconnu. Il constate les discussions entre juristes. Il donne son sentiment, et le peuple tranche”. Según A. Peyreffite, de Gaulle no respondió nada. (Peyreffite, 1994, p. 230).
} 
Nótese que la interpretación auténtica dada por una autoridad no jurisdiccional es una decisión que puede ser, a veces, interpretada por otra autoridad como "ilícito penal". Tal es el caso del artículo 16 de la Constitución francesa de 1958: el presidente de la República bien puede interpretar tal o cual circunstancia como apta para justificar la puesta en marcha de los "poderes de crisis", pero esta interpretación puede ser interpretada a su vez por el Parlamento como constitutiva de alta traición. Si el primero toma su decisión considerando la posible decisión del segundo, la interpretación auténtica es una actividad ejercida en común y su producto es el resultado de una relación de fuerzas entre dos autoridades competentes.

\subsection{El producto de la interpretación}

Si la interpretación es una decisión, esta decisión tiene como objeto la producción de normas pertenecientes al nivel jerárquico del enunciado interpretado. Así, según la fórmula frecuentemente citada por el obispo Hoadly: "whoever hath an absolute authority to interpret any written or spoken laws, it is he who is truly the Law-giver to all intents and purposes, and not the person who first wrote or spoke them" (Gray, 1927, p. 102)

En consecuencia, se debe decir que una corte, como nuestra Corte de Casación, encargada de controlar la aplicación de las leyes — y, por ende, de interpretarlas — dispone de un poder legislativo. Se trata, sin embargo, de un poder legislativo solamente parcial. La razón no es - como se podría estar tentado de creer- que antes de cualquier interpretación todo texto debe haber sido adoptado por el poder legislativo "oficial": el poder de interpretar puede ejercerse sobre cualquier texto, y las normas de rango legislativo pueden ser insertadas sobre los más diversos enunciados. No es por esto: si la Corte no es más que un colegislador, es porque su decisión puede siempre ser superada por un nuevo texto legislativo. Sin duda, este nuevo texto, a su vez, podrá ser también interpretado, pero en la "prueba de fuerza" que de este modo se instaura, la Corte no tiene la seguridad de tener la última palabra.

De la misma manera, una corte constitucional comparte el poder constituyente (es co-constituyente). Puede también interpretar libremente la constitución y su interpretación puede ser incorporada en los más diversos enunciados constitucionales o incluso producirse en la ausencia de enunciados, como lo hace, a veces, cuando proclama principios no escritos. Pero la corte constitucional también puede ver sus decisiones superadas por un nuevo texto constitucional producido por el poder constituyente. Solo en el caso de que la corte logre dotarse de un poder de controlar ampliamente la validez de las leyes de revisión constitucional es que debería ser considerada, no como co-constituyente, sino como poder constituyente sin más.

Pero la interpretación auténtica es, sobretodo, una fuente de poderes formidables si permite a una autoridad extender su competencia. Es lo que sucede cuando la competencia de la autoridad en cuestión se deriva de textos sujetos a su propia interpretación. La Corte Suprema de los Estados Unidos interpretó, en 1803, la Constitución americana en el sentido de que ella le confería el poder de controlar la constitucionalidad de las leyes. El Conseil constitutionnel francés procedió de la misma manera en Francia, en 1971.

En este punto, a la teoría realista de la interpretación se opone frecuentemente un "razonamiento de lo absurdo": esta teoría, se dice, supondría invertir completamente la jerarquía de normas; en efecto, la constitución no sería una norma sino solo por la interpretación del legislador, la ley por la de los tribunales y así sucesivamente hasta la ejecución material, hasta el punto de que la autoridad suprema sería el policía (De Béchillon, 1994, p. 247) ${ }^{6}$.

\footnotetext{
${ }^{5}$ Cita retomada por Kelsen (1945, p. 152).

${ }^{6}$ Cfr. réplica de Troper (1994, p. 267).
} 
Sin embargo, la objeción puede ser fácilmente descartada. La jerarquía del orden jurídico no es en modo alguno una jerarquía de enunciados o textos. Entre dos textos no puede existir relación jerárquica, sino solamente entre los contenidos o significados de esos textos. Pero si alguien determina simultáneamente el significado del texto de la constitución y del texto de la ley, es decir, si determina las dos normas, establece al mismo tiempo la existencia de una jerarquía entre ellas, que no es opuesta sino idéntica a la jerarquía tal como se la presenta habitualmente. La norma legislativa, determinada por el proceso de interpretación, encuentra el fundamento de su validez o, si se lo prefiere, es presentada como obligatoria, en razón de su conformidad con la norma constitucional, así como es determinada por la interpretación. Dicho de otra manera, del hecho de que la validez provenga del proceso de producción de normas inferiores resulta, no que la jerarquía sea invertida, sino solamente que esta debe ser considerada interna al discurso del intérprete.

Con respecto a la idea de que es el policía el que interpretaría la decisión del tribunal, ha de decirse que no es falsa, pero no se puede olvidar que esta interpretación no es en modo alguno auténtica. Tal interpretación puede ser contestada y anulada por la de un tribunal. En otros términos, según la teoría realista, la jerarquía de normas refleja aquella de los poderes.

\subsection{La libertad del intérprete}

Se opone entonces a la teoría realista otra objeción según la cual el intérprete, especialmente cuando se trata de un juez, está sometido a múltiples restricciones, de manera que no se podría decir que es libre y que expresa libremente su voluntad ${ }^{7}$. En realidad, este argumento descansa sobre una confusión entre libre albedrío y libertad en el sentido jurídico.

Cuando se afirma que una autoridad cualquiera, un órgano del ordenamiento jurídico, es libre, evidentemente no se quiere decir que se halla sustraído de todo determinismo. Por ejemplo, la teoría tradicional admite que, en ausencia de un control de legitimidad constitucional, el legislador es libre de adoptar leyes que tengan un contenido cualquiera, reconociendo, empero, que cuando el parlamento vota no escapa a la causalidad y que se encuentra sometido a toda suerte de vínculos. La libertad del matrimonio no significa que la decisión de casarse y la elección del cónyuge no estén sometidas a ninguna clase de influencia social o psicológica, sino solamente que cualquier decisión al respecto es considerada por el derecho como válida. Lo que entendemos aquí por "libertad" no hace alusión a una situación carente de todo determinismo, sino solamente una libertad "jurídica”.

Una autoridad es jurídicamente libre si puede escoger entre varias conductas igualmente válidas para el derecho, incluso su elección es, de hecho, producto del determinismo. Así, la afirmación según la cual la interpretación es libre significa solamente que cuando una autoridad está investida del poder de dar una interpretación auténtica: todas las interpretaciones dadas por esta autoridad serán igualmente válidas o, en otros términos, se incorporarán al texto interpretado; y, entonces, producirán efectos jurídicos, lo que, a decir verdad, no es más que otra manera de afirmar que se trata de una interpretación auténtica. Esto no supone de modo alguno oponerse a que el comportamiento del intérprete obedezca a múltiples causas. Por lo demás, las críticas no se equivocan, puesto que reprochan, precisamente a la teoría de la "interpretación-voluntad" formulada por los realistas americanos, el hacer de la sentencia el resultado de la calidad del desayuno del juez.

Los límites del argumento según el cual existen restricciones en la interpretación aparecen claramente si se considera al régimen despótico, tal como es definido por

\footnotetext{
${ }^{7}$ Esta objeción ha sido realizada, en particular, por de Béchillon (1994), así como por G. Vedel en su intervención oral en el seminario (en Troper, 1995).
} 
Montesquieu: un sistema donde uno solo gobierna, no según las leyes, sino según sus caprichos. El déspota goza, entonces, de la más total de las libertades jurídicas. Y, sin embargo, también él se encuentra sometido a limitaciones de toda clase, que resultan de la situación económica del país, del riesgo de que los súbditos opongan resistencia, de que sus decisiones sean mal ejecutadas, etc. Una decisión que ignorase estos límites, afectaría sin duda a la eficacia de la acción. Sería, sin embargo, válida.

El análisis puede llevarse aún más allá. Es justamente porque admite que la interpretación es jurídicamente libre que la teoría realista puede entender que está sometida a un determinismo. Por el contrario, una teoría que admite que la interpretación consiste en descubrir un significado que ya está en el texto (que preexiste) no puede sino inquirirse acerca de lo que el intérprete debe hacer, inhibiéndose de explicar lo que realmente hace.

Quedan dos fenómenos por explicar.

Los jueces son libres de interpretar según su voluntad. Y, sin embargo, expresan con mucha constancia el sentimiento de estar obligados como para que se pueda dudar de este sentimiento. No es suficiente, por lo demás, afirmar que son victimas de una ilusión, ya que aún haría falta entender aquello que puede provocar una ilusión tan común.

Por otro lado, si los jueces no están vinculados por un significado preexistente del texto, y si no hacen más que expresar su voluntad, pueden entonces modificar a placer sus interpretaciones en función de sus caprichos. Sin embargo, la jurisprudencia presenta una coherencia suficiente como para que las decisiones no sean totalmente imprevisibles.

Se podría atribuir estos fenómenos a la formación de los jueces y a la ideología de la que están impregnados; ideología que busca que la función judicial sea una función de aplicación y no de creación del derecho. Se podría también invocar la consciencia de todo detentor del poder de estar sometido a límites de hecho. Ni la una ni la otra explicación persuaden.

La primera, porque la norma que prescribe al juez aplicar el derecho y no crearlo es una norma moral y no una norma jurídica. Ciertamente, se pueden hallar disposiciones de derecho positivo que ordenan precisamente al juez limitarse a aplicar los textos, pero estas disposiciones tienen que ser ellas mismas interpretadas antes de ser aplicadas, y aquí la pregunta se impone de nuevo: ¿qué cosa obliga a aplicarlas? Lo que crea esta obligación de aplicar las normas del sistema jurídico, entonces, no puede ser más que una norma exterior al mismo sistema.

Sin embargo, el sentimiento de los jueces es que están obligados, no moralmente, sino jurídicamente. Por otra parte, si se tratase realmente de una obligación moral, esta no sería sentida de la misma manera por todos los jueces, que obedecen, por supuesto, a morales diferentes. De hecho, esta norma sería, con seguridad, a menudo transgredida, especialmente en caso de conflicto con otras normas morales. Finalmente, y, sobre todo, la norma que prescribe aplicar el derecho no tiene ningún contenido específico en cuanto a la conducta interpretativa que conviene adoptar. Incluso si prescribe interpretar el texto conforme a su sentido "verdadero", no prescribe la manera de descubrirlo; y si el juez experimentase solamente el sentimiento de estar obligado, no tendría también el sentimiento de estar obligado a interpretar en un sentido en lugar de otro.

En cuanto a la idea de que los jueces tendrían, simplemente, consciencia de estar sometidos a limitaciones (vínculos) de hecho, esta no deja percibir el sentimiento que expresan de tener ciertas obligaciones. Contrariamente al déspota, que puede tener el sentimiento de estar sometido a limitaciones de hecho, pero no a obligaciones, el juez no considera simplemente que una decisión o una interpretación es inoportuna debido a sus consecuencias, sino que es válida o inválida en derecho. 
Entonces, se debe tomar en serio a la idea de que el derecho no contiene solamente obligaciones (que se podrían fácilmente desconocer o transgredir, y que, en este caso, como ya se vio, no existen), sino que produce una serie de limitaciones, que podemos llamar "restricciones jurídicas". Si esta hipótesis fuese verificada, se debería admitir que, junto a las limitaciones de hecho, que dependen de la naturaleza o la sociedad, hay también restricciones que resultan del sistema jurídico, restricciones que hacen que los agentes — que tienen el derecho de escoger entre un gran número de conductas posibles - vean a esta, sin embargo, como una elección estrechamente limitada.

Ciertamente la expresión "restricción jurídica” parece contener una contradicción en los términos, ya que el concepto de restricción se inscribe en el de determinismo, que pertenece al sein y no al sollen. Ahora bien, se puede concebir la existencia de dos tipos de restricciones comparables a limitaciones materiales y que se derivan del sistema jurídico.

Las restricciones en sentido fuerte se derivan de reglas constitutivas, es decir, de reglas que no se limitan a prescribir una conducta, sino que la constituyen en el sentido de que es la observancia de tales reglas lo que permite calificarla (Searle, 1972, p. 72). Así, por ejemplo, "el matrimonio debe ser celebrado por un funcionario del registro civil" significa que una ceremonia que fuese celebrada por alguien distinto de un funcionario del registro civil no sería un matrimonio en el sentido jurídico del término. Un matrimonio solo puede ser definido como una unión celebrada de cierta manera. Las reglas de este tipo producen un verdadero límite, en la medida en que se presentan como medios necesarios para realizar un cierto fin: el único medio para casarse es celebrándolo frente al funcionario del registro civil. Tales límites, sin embargo, no pesan sobre la actividad interpretativa. No existe ninguna regla cuya observancia permita calificar un acto como interpretación jurídica, menos todavía calificarlo como interpretación justa. Después de todo, si reglas de este tipo existiesen, habría que interpretarlas.

A su turno, se puede hablar de restricciones jurídicas en sentido débil, allí donde las normas coloquen a un individuo o a un órgano en una situación tal en que deba comportarse de cierta manera para actuar de modo razonable y eficaz. Una situación tal se encuentra, ante todo, en el caso de órganos jurisdicciones colegiados, cuando uno de los miembros pretende persuadir a sus colegas. Incluso si está perfectamente convencido de la verdad de la tesis realista, le es evidentemente imposible afirmar que el juez puede atribuir al texto normativo cualquier significado, y que, fuera del argumento de oportunidad, no hay ninguna razón para preferir un significado en lugar de otro. Se puede sostener, entonces, que existe un límite objetivo que empuja a recurrir a argumentos que apelan a la verdad del texto (Meunier, 1994).

Una situación de restricción débil se encuentra toda vez que las normas organizan las relaciones entre las autoridades, de tal manera que el poder discrecional de unos disuade a los otros de ejercer su propio poder discrecional de manera excesiva.

Así, todos los sistemas del equilibrio de poderes, tal como se los concebía en las constituciones de fines del siglo XVIII, están precisamente organizados de modo tal que de ellos resulte una legislación y una práctica política "moderada" en el sentido de Montesquieu: las cámaras se abstendrán de adoptar leyes excesivas porque el rey opondría su veto. El rey no adoptará ninguna decisión contraria a las leyes porque sus ministros se negarían a suscribirla. Así mismo, el presidente de la V República dudará en cuanto a la posibilidad de interpretar las circunstancias como suponiendo una amenaza grave e inmediata, sabiendo que el Parlamento puede interpretar su comportamiento como constitutivo del crimen de alta traición. 
La restricción, en este caso, debe ser considerada como "débil" porque tales comportamientos no son imposibles (como podría ser un matrimonio celebrado fuera de las formas prescritas). Estos comportamientos pueden perfectamente producirse y ser calificados conforme a las intenciones de sus autores. En el caso de la aprobación de una ley excesiva en su contenido, no se trataría siquiera de una transgresión, y el veto regio no sería una sanción. Simplemente, tal actitud no sería razonable, mientras que — por lo menos según la opinión de los publicistas del siglo XVIII — sería preferible adoptar una ley de compromiso que arriesgarse a que no haya ley.

También puede ocurrir que las situaciones que resultan de un conjunto de normas en vigor induzcan a adoptar una conducta moderada, no para evitar consecuencias desagradables, sino para acrecentar su poder. La paradoja no es sino aparente, y resulta de una percepción del poder perfectamente ilustrada por la descripción montesquiviana del despotismo. Contrariamente a la monarquía, en donde uno solo gobierna, si bien mediante "leyes fijadas y establecidas", el despotismo es un sistema donde uno solo gobierna, pero sin leyes, según sus caprichos. Así, el poder del déspota es, según Montesquieu, más grande que aquel del rey; ello, porque no está limitado por ninguna ley y porque no tiene otro objetivo sino "las delicias del príncipe" (les délices du prince). La omnipotencia del déspota es concebida de manera puramente negativa, como aquella del rey de Francia que es legibus solutus y a la imagen de Dios, si es definida como la capacidad de hacer milagros, es decir, de sustraerse a las leyes de la naturaleza o de cambiarlas en todo momento.

En cambio, si se define el poder de manera positiva, como la capacidad de determinar el comportamiento de otros, entonces se acrece el propio poder, no ya decidiendo según los caprichos personales, sino, por el contrario, enunciando reglas generales y estables que permitirán a los hombres prever las consecuencias de sus acciones; y, entonces, escoger, de entre las conductas posibles, aquellas que le serán más provechosas. Apartándose de las leyes, se emiten prescripciones válidas para acciones particulares; sometiéndose a ellas se dispone para una clase de acciones.

Nada impide al Consejo de Estado o a la Corte de Casación dar, a cualquier texto, cualquier significado, puesto que toda interpretación será igualmente válida, pero si se comportasen así, está claro que las jurisdicciones inferiores y los justiciables serían incapaces de regular sus propias conductas, porque les sería imposible prever las consecuencias de sus actos.

En el caso del juez constitucional, no hay jurisdicciones inferiores, pero el legislador es un "justiciable": no solo que una serie de interpretaciones arbitrarias podrían conducir a un cuestionamiento de la legitimidad del juez constitucional, sino, sobretodo, que este no podría contribuir a determinar, como lo hace, el contenido de la legislación futura. La conciencia de la estabilidad de la jurisprudencia es lo que permite al legislador hacer una estimación razonable de la licitud, y entonces de la viabilidad, de sus acciones. Por lo demás, por jurisprudencia tiene que entenderse, aquí, no simplemente las reglas que resultan del conjunto de las decisiones jurisdiccionales, sino también los métodos y sistemas de conceptos que permiten lograrlo. Es empleando los mismos métodos y conceptos que los justiciables, como también las otras autoridades, podrán esperar prever las decisiones jurisdiccionales, conocer las reglas a las cuales están sometidos y, así, reglar sus propias conductas.

\section{Referencias bibliográficas}

de Béchillon, D. (1994). "L'ordre de la hiérarchie des normes et la théorie réaliste de l'interpretation - réflexions critiques", Revue de la Reserche Juridique 1. 
Gray, J. (1927). The Nature and Sources of the Law. New York: Columbia University Press. Kelsen, H. (1945). General Theory of Law and State. New York: Russell \& Russell.

Meunier, J. (1994). Le pouvoir du Conseil Constitutionnel. Essai d'analyse stratégique. Paris: LGDJ.

Peyreffite, Alain (1994). C'était de Gaulle. Paris: Fayard.

Searle, J. R. (1972). Les actes de langage. Paris: Hermann.

Troper, M. (1994). "Le réalisme et le juge constitutionnel", Revue de la Reserche Juridique 1

(1995). La liberté d'interprétation du juge constitutionnel, en P. Amselek (ed.), Interprétation et droit, Bruxelles: Bruylant et PU d'Aix Marseille, pp. 235-ss.

(1999). "Una teoria realista dell'interpretazione". Materiali per una storia della cultura giuridica, XXIX, 2, 473-493.

(2006). "Une théorie réaliste de l'interpretation". Revista Opinao Juridica, 8 (2), 301-318. 